\title{
Micro light plates for low-power photoactivated (gas) sensors
}

Cite as: Appl. Phys. Lett. 114, 053508 (2019); https://doi.org/10.1063/1.5078497

Submitted: 25 October 2018 . Accepted: 22 January 2019. Published Online: 06 February 2019

Nicolai Markiewicz (iD), Olga Casals (D), Cristian Fabrega (iD), Isabel Gràcia (D), Carles Cané (D), Hutomo Suryo Wasisto, Andreas Waag, and Joan Daniel Prades (D)

ARTICLES YOU MAY BE INTERESTED IN

Thermophotonic cooling in GaAs based light emitters

Applied Physics Letters 114, 051101 (2019); https://doi.org/10.1063/1.5064786

Single-pixel phase imaging by Fourier spectrum sampling

Applied Physics Letters 114, 051102 (2019); https://doi.org/10.1063/1.5087174

Wideband electromagnetic dynamic acoustic transducers (WEMDATs) for air-coupled ultrasonic applications

Applied Physics Letters 114, 053505 (2019); https://doi.org/10.1063/1.5086383

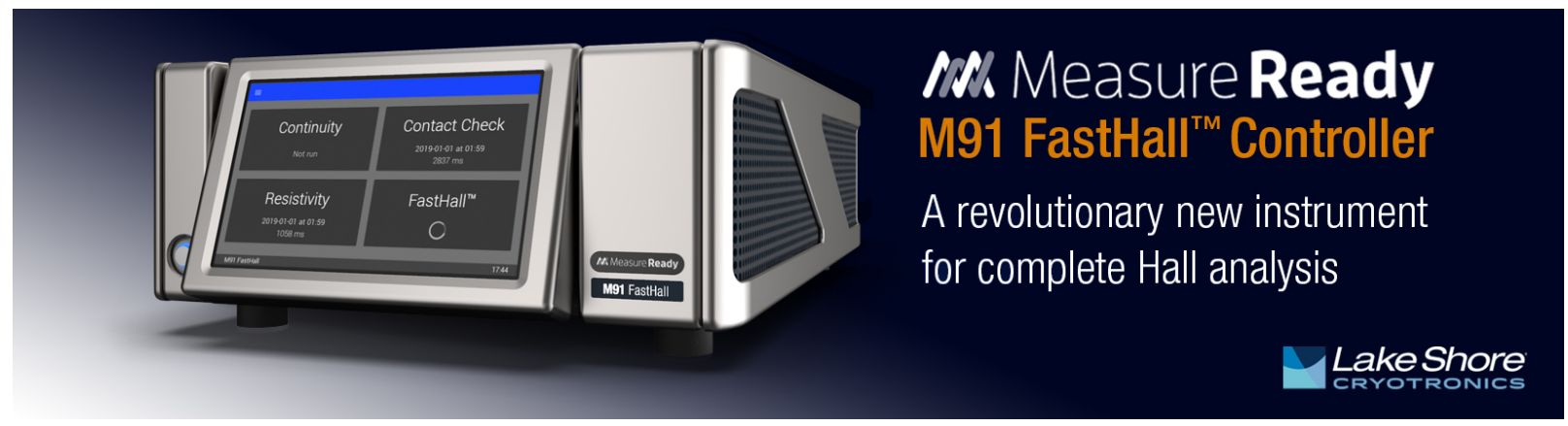




\title{
Micro light plates for low-power photoactivated (gas) sensors
}

Cite as: Appl. Phys. Lett. 114, 053508 (2019); doi: 10.1063/1.5078497

Submitted: 25 October 2018 . Accepted: 22 January 2019 .

Published Online: 6 February 2019

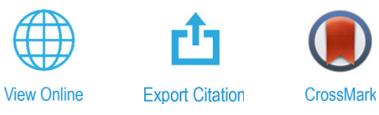

Nicolai Markiewicz,,2 (D) Olga Casals,,a) (D) Cristian Fabrega,' (D) Isabel Gràcia, ${ }^{3}$ (D) Carles Cané, Hutomo Suryo Wasisto, ${ }^{2,4}$ Andreas Waag, ${ }^{2,4}$ and Joan Daniel Prades ${ }^{\top}$

\begin{abstract}
AFFILIATIONS
${ }^{7}$ MIND-IN²UB, Department of Electronics and Biomedical Engineering, Universitat de Barcelona, E-08028 Barcelona, Spain

${ }^{2}$ IHT-LENA, Technische Universität Braunschweig, D-38106 Braunschweig, Germany

${ }^{3}$ IMB-CNM (CSIC), Institut de Microelectrònica de Barcelona, Campus UAB, E-08193 Bellaterra, Spain

${ }^{4}$ Epitaxy Competence Center $\left(\mathrm{ec}^{2}\right)$, Technische Universität Braunschweig, D-38106 Braunschweig, Germany
\end{abstract}

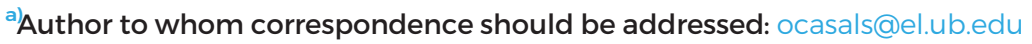

\begin{abstract}
We report a miniaturized device integrating a photoactive material with a highly efficient Light Emitting Diode light source. This so-called micro light plate configuration allows for maximizing the irradiance impinging on the photoactive material, with a minimum power consumption, excellent uniformity, and accurate control of the illumination. We demonstrate these advantages with an example application: photoactivated gas sensors with a power consumption as low as $30 \mu \mathrm{W}$ (this is 1000 times lower than the best figures reported to date). The letter also presents a quantitative model and a set of design rules to implement it in further integrated applications.
\end{abstract}

Published under license by AIP Publishing. https://doi.org/10.1063/1.5078497

Many transduction mechanisms based on the physicochemical properties of materials require excitation with an external source of energy. This is the case, for example, of fluorescence sensors, ${ }^{1-3}$ photocatalysis devices, ${ }^{4}$ or conductometric gas/chemical sensors. In this latter kind of devices, the presence of gaseous molecules is monitored by measuring the changes in the electric resistance of a gas-sensitive semiconductor material (like a metal oxide ${ }^{5}$ or a carbon allotrope ${ }^{6}$ ), which is usually activated with either heat ${ }^{7-9}$ or light. $^{10}$

The former has been the standard approach in the field. Most commercial devices operate in temperature-controlled conditions at temperatures above $200{ }^{\circ} \mathrm{C}$ and incorporate an electric heater to that end. This is, however, a power demanding component that limits the applicability of these devices to scenarios where power availability is not a concern. To mitigate this issue, intensive efforts have been devoted to reducing the power consumption of the heaters by means of miniaturization. ${ }^{8}$ As a result, many kinds of micro heaters and micro hot plates ${ }^{11-14}$ have been reported to date, showing significant improvements in terms of thermal insulation and thermal efficiency. As a rule of thumb, this meant lowering the power requirements of these devices from a few watts to only several tens of milliwatts. ${ }^{13}$ With the advent of the Internet of Things (IoTs) and the increasing need of ultra-low-power wireless autonomous devices, these power loads are deemed still too high and do not meet the prerequisites of upcoming devices. ${ }^{15}$

In this context, light activation can be an alternative to achieve equivalent performances with sub-milliwatt power requirements. ${ }^{10}$ On the one hand, it has been widely demonstrated that light can be used to stimulate the response to gases in several semiconductor materials. ${ }^{16-30}$ On the other hand, however, this possibility has been mostly explored to date at a research level using macroscopic light sources (MLS), like discharge lamps or encapsulated Light Emitting Diodes (LEDs), ${ }^{16-18,20-22,24-26,31}$ which require accurate optical alignment. Consequently, this approach is generally associated with complex operation, lack of reproducibility, and poor control of the excitation conditions.

Only a few research groups worked on the issues of constructing solid and robust devices. Gong et al. proposed coating an optical fiber with the sensor material, leading to a compact sensor header that still required an external light source. ${ }^{27}$ Wang et al. reported the first full stack combining an InGaN LED with a sensor material film at both sides of a sapphire substrate, with a sensor-to-light source distance in the range of several hundreds of microns. ${ }^{19}$ A similar setup was reported by Yu et al., but in that case the LED and the sensor film were glued together. ${ }^{23}$ More recently, the direct growth of a sensor material 
(i.e., $\mathrm{ZnO}$ nanowires) on top of the outcoupling lenses of a commercial LED has been reported by Hsu et al. ${ }^{28}$ However, any of the proposals reported so far offer a truly scalable solution that could be fabricated in large volumes, with good reproducibility and at a low cost using the methods and tools commonly available in a microelectronic foundry. Moreover, previous publications reported power requirements well above $10 \mathrm{~mW}$, and none of them has yet addressed the power consumption issue.

In this work, we report the monolithic integration of an LED with a photoactive sensor material aiming at power efficiency that can be reproduced with industry-standard methods. Due to its similarities with the micro hot plates, where micro integration and intimate contact between the heater and the material were key to improve efficiency, we call this approach "micro light plates" or $\mu \mathrm{LP}$. As demonstrated below, the $\mu \mathrm{LPs}$ allow for lowering the power requirements down to microwatts, and guarantee a fine control and uniformity of the light irradiance over the illuminated material, as well as an excellent reproducibility among samples.

Figure 1 shows a sketch comparing the configurations implemented to date (referred to as "macroscopic light source" or MLS) with our proposal ("micro light plate" or $\mu \mathrm{LP}$ ). In both cases, the sole parameter that determines the effect of the illumination on the sensor material is the flux density or irradiance $\left(E_{e}\right)$ impinging locally on the sensor surface, ${ }^{10,20}$ this is, the radiant flux or radiant power $\left(\Phi_{e}\right)$ per surface unit (area, A), $\mathrm{E}_{e}=\delta \Phi_{e} / \delta \mathrm{A}$.

The irradiance $\mathrm{E}_{e, \mathrm{PD}}$ reaching a point detector $(\mathrm{PD})$ at a distance $d$ of an extended light source (of area $A_{S}=\pi \times r_{S}^{2}$ ) can be written as ${ }^{32-34}$ [see supplementary material S.1 and scheme in Fig. 1(c)]

$$
\mathrm{E}_{e, \mathrm{PD}}\left(d, r_{\mathrm{S}}, g, \mathrm{~L}_{e, 0}\right)=\frac{\delta \Phi_{e}}{\delta \mathrm{A}_{\mathrm{PD}}} \approx \frac{2 \pi \mathrm{L}_{e, 0}}{g}\left(\frac{\left(1+\left(\frac{r_{\mathrm{S}}}{d}\right)^{2}\right)^{g / 2}-1}{\left(1+\left(\frac{r_{\mathrm{S}}}{d}\right)^{2}\right)^{g / 2}}\right),
$$

where $\mathrm{L}_{e, 0}=\left(g \times \Phi_{e}\right) /\left(2 \pi \times \mathrm{A}_{\mathrm{S}}\right)$ is the radiance in the direction normal to the source surface, and $g$ is a coefficient that depends on the light emission pattern (e.g., $g=2$ for Lambertian sources like a surface-emitting LED ${ }^{35}$ ). In Fig. 1(c), we plotted the dependence of $E_{e, P D}$ (normalized to the source radiant exitance or emittance $M_{e, S}$; this is, the irradiance right at the source surface $\left.E_{e, P D}\right|_{d=0}$ ) on the $r_{\mathrm{S}} / d$ ratio (source radius divided by source-to-detector distance) for different $g$ values. Two limits for low and high $r_{\mathrm{S}} / d$ ratios are clearly observed, independent of the emission pattern $g$.

In the lower limit $\left(r_{S} / d \rightarrow 0\right)$, which corresponds to the MLS configuration with large distances and/or small source sizes, Eq. (1) can be approximated by

$$
\mathrm{E}_{e, \mathrm{MLS}} \underset{\left(\mathrm{r}_{\mathrm{S}} / \mathrm{d}\right) \rightarrow 0}{\approx} \frac{\mathrm{I}_{e, 0}}{d^{2}}=\frac{g \Phi_{e, \mathrm{MLS}}}{2 \pi d^{2}}=\frac{g \eta_{\mathrm{c}, \mathrm{MLS}}}{2 \pi} \frac{\mathrm{P}_{\mathrm{MLS}}}{d^{2}},
$$

where $I_{e, 0}=g \Phi_{e} / 2 \pi$ [see supplementary material S.1.(a)]. The radiant power $\left(\Phi_{e}\right)$ is here expressed in terms of the electrical power applied to the LED ( $\left.P_{\text {MLS }}\right)$ and its efficiency to convert it into light (i.e., the power conversion efficiency $\left.\eta_{c, M L S}\right)$. The expression states clearly that, given a certain amount of electrical power applied to a macroscopic light source $P_{M L S}$, its ability to influence the optoelectronic properties of the sensor material (i.e., the $\mathrm{E}_{e, \mathrm{MLS}}$ ) decays with the square of the distance. Besides, under these conditions, the irradiance would not depend on the shape or on the size neither of the source nor of the sensing layer. So, in order to decrease the electrical power $P_{\text {MLS }}$ needed to attain certain irradiance levels with a macroscopic setup we need: (1) to work at a quite short distance (which normally is limited by practical issues when combining discrete components, and leads to non-uniform irradiance patterns); (2) to increase the power conversion efficiency $\eta_{c, M L S}$ (which is a parameter intrinsic of the LED technology used); or (3) to increase the emission pattern $g$ (which depends again on the LED technology and/or may involve the use of lenses in the encapsulation).

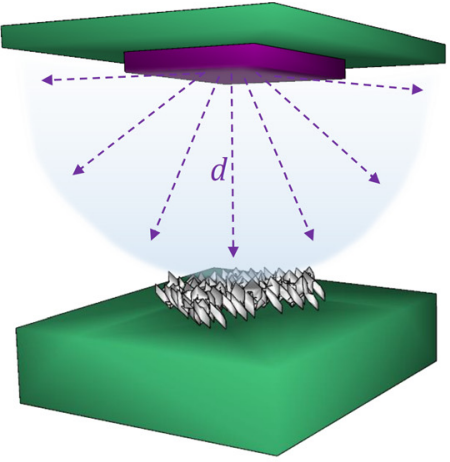

(a) Macroscopic Light Source (MLS)

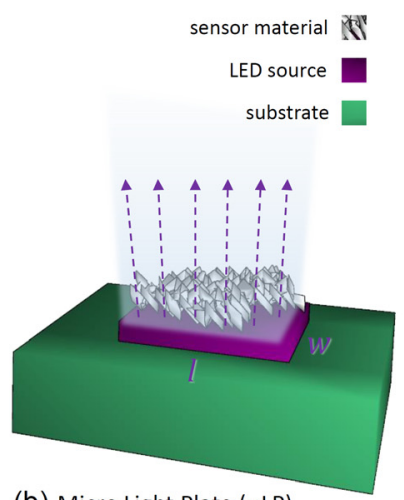

(b) Micro Light Plate $(\mu \mathrm{LP})$

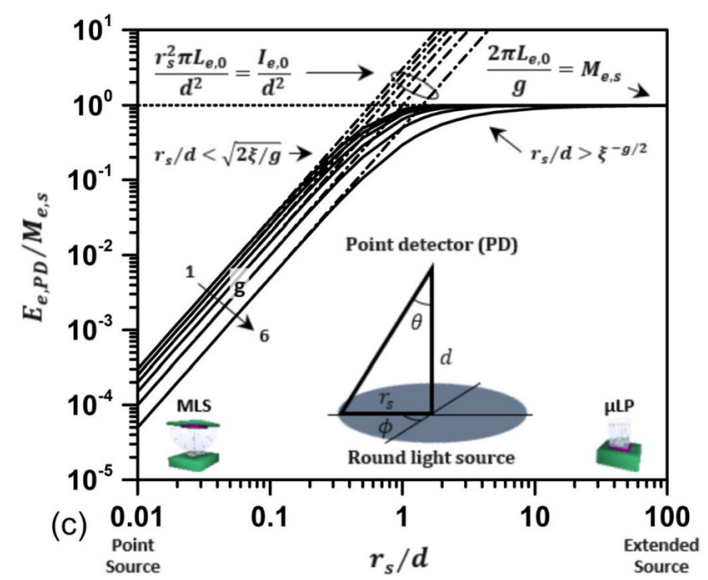

FIG. 1. Schemes of different light spreading scenarios. (a) At macroscopic distances, in the Macroscopic Light Source (MLS) approximation, light spreading is significant. (b) In contrast, light spreading is negligible right at the surface of the Micro Light Plate $(\mu \mathrm{LP})$. Moreover, in the $\mu \mathrm{LP}$, all the geometric parameters that determine the illumination conditions are fixed and set during the fabrication process. (c) Irradiance received at a point detector $\left(E_{e, P D}\right)$ from a round light source-normalized to the source radiant exitance $\left(M_{e, s}\right)$-versus the $r_{s} / d$ ratio (source radius divided by source-to-detector distance), for different light source emitting patterns $(g$ from 1 to 6$)$ according Eq. (1). The inset scheme illustrates the different geometric parameters. The trends of the two extreme limits (point source and extended source) are also plotted in the figure with discontinuous lines, as well as the ranges of $r_{s} / d$ where these approximations are valid with an uncertainty $\xi$. 
These fundamental reasons may explain why power efficient devices have not been achieved with the MLS configuration. Also, its strong dependence with the optical alignment and distance between the light source and the sensor material is the reason behind its complex implementation and reproducibility.

In the opposite limit $\left(r_{S} / d \rightarrow \infty\right)$, i.e., short distances and sizeable source areas, $E_{e, P D}$ is independent on the distance and equals to the radiant exitance of the source $\left(\mathrm{M}_{e, s}\right)$

$$
E_{e, \mu \mathrm{LP}} \underset{\left(r_{s} / \widetilde{d}_{) \rightarrow \infty}\right.}{\approx} M_{e, \mu \mathrm{LP}}=\frac{\Phi_{e, \mu \mathrm{LP}}}{w \times l}=\eta_{\mathrm{c}, \mu \mathrm{LP}} \frac{\mathrm{P}_{\mu \mathrm{LP}}}{w \times l} .
$$

This is the case of the $\mu \mathrm{LPs}$, in which $d$ is the thickness of the insulator layer needed to separate electrically the LED top electrode and the sensing layer (a few hundreds of nanometers in practical realizations), and $r_{\mathrm{S}}$ compares to the size of the interdigitated electrodes (IDEs) (on the order of hundreds of microns to facilitate the material deposition). Therefore, they usually differ in about three orders of magnitude, making the conditions for irradiance invariance easy to fulfill with the $\mu \mathrm{LP}$ approach. Eq. (3)-where we expressed the irradiance in terms of the $\mu \mathrm{LP}$ area $\left(\mathrm{A}_{\mu \mathrm{LP}}=\mathrm{A}_{\mathrm{LED}} \approx \mathrm{A}_{\mathrm{IDE}}=w \times l\right)$, the electrical power $\left(\mathrm{P}_{\mu \mathrm{LP}}\right)$, and the power conversion efficiency $\left(\eta_{c, \mu \mathrm{LP}}\right)$, which depends on the bias conditions (inset in Fig. 3)-clearly shows that (1) the irradiance will be constant and uniform at all the points of the sensing layer [if it is slightly smaller than the LED, see supplementary material S.1.(b)], and (2) the irradiance depends only on the electrical power density (i.e., per unit area) and the conversion efficiency, but not on the total device area. Therefore, the electrical power $\mathrm{P}_{\mu \mathrm{LP}}$ needed to reach certain working conditions (i.e., $\mathrm{E}_{e \mu \mathrm{LP}}=$ const.) can be systematically reduced by miniaturizing the $\mu \mathrm{LP}$ (i.e., reducing $\mathrm{A}=w \times l$ ). Moreover, these geometrical factors will be set once and forever during the fabrication stage, leading to robust and easy to reproduce devices.

To demonstrate this analysis, we produced a series of monolithic devices integrating (1) an LED light source, (2) a pair of interdigitated electrodes (IDEs) to read the electrical resistance of the material, and (3) a sensor material. The devices were directly fabricated on sapphire wafers carrying the asgrown LED structure (Fig. 2) with a dominant emission wavelength of $455 \pm 3 \mathrm{~nm}$ with a FWHM of $18.5 \pm 1.5 \mathrm{~nm}$. Details about the fabrication process can be found in the supplementary

(a)
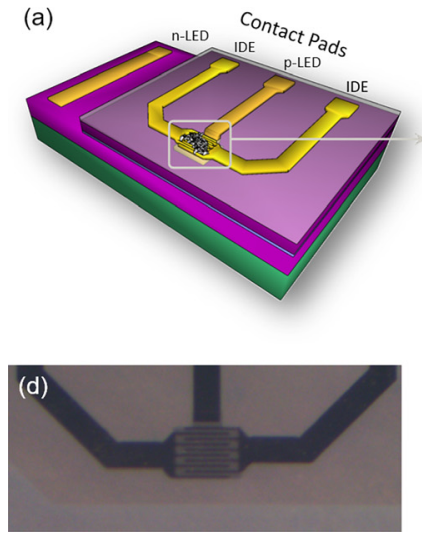

(b)
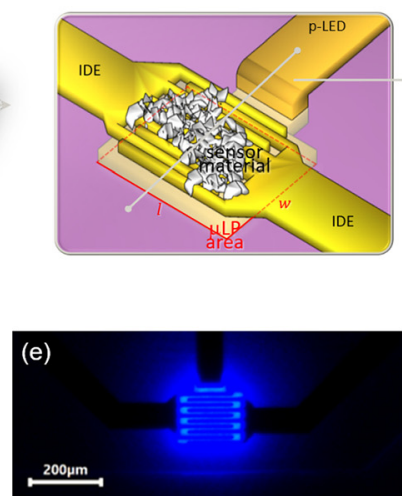

material S.2.(a). The $p$-GaN anode was semitransparent $\left(\mathrm{T}_{455 \mathrm{~nm}}=47 \%\right)$ to allow the light to come through. The low lateral conduction in the $p$-GaN limited the emission of light to the area immediately below the $p$-GaN anode [ $\mu$ LP area" in Figs. 2(b) and 2(c), with dimensions of approximately $w=190 \mu \mathrm{m}$ by $l$ $=250 \mu \mathrm{m}]$. The pair of Inter Digitated Electrodes (IDEs) was deposited right on top of the $p$-GaN electrode, using an intermediate layer of $350 \mathrm{~nm}$ of $\mathrm{SiO}_{2}$ to electrically insulate them [Figs. 2(b) and 2(c)]. All the electrodes were extended beyond the $\mu \mathrm{LP}$ area, running on top of the insulating $\mathrm{SiO}_{2}$ layer, to build thicker pads easily accessible by wire bonding.

As a proof-of-concept, ZnO nanoparticles (NPs) smaller than $130 \mathrm{~nm}$ were deposited as a sensor material on top of the IDEs by means of micro-drop casting, following a procedure reported elsewhere ${ }^{36,37}$ [see more details in supplementary material S.2.(b)]. The final distance between the sensor material (ZnO NPs) and the light emitting surface ( $p$-GaN electrode) was only $350 \mathrm{~nm}$ (i.e., the thickness of the insulating oxide). This is about three orders of magnitude closer than any other previous reports attempting device integration. ${ }^{19}$ It is worth stressing that at such short distances, the irradiance on the sensor material (1) decays only by $5 \times 10^{-4} \%$ compared to the LED radiant exitance $\mathrm{M}_{e, \mu \mathrm{LP}}$, and (2) is very uniform throughout the sensor layer, varying less than $0.12 \%$ due to edge effects.

Figure 3 shows the irradiance $\mathrm{E}_{e, \mathrm{ZnO}}$ impinging on the material (ZnO NPs) versus the electrical power $\mathrm{P}_{\mu \mathrm{LP}}$ applied to our $\mu \mathrm{LPs}$ (black line). The radiant flux was measured on a bare $\mu \mathrm{LP}$ (i.e., without $\mathrm{ZnO}$ ) using an Illumia ${ }^{\circledR}$ lite Portable Light Measurement System (from Labsphere, Inc.), and from this data the irradiance was calculated with Eq. (3). For comparison with the MLS approach [see supplementary material S.2.(c)], we illuminated the sensing layer on the $\mu \mathrm{LP}$ device with another bare $\mu \mathrm{LP}$ device (i.e., without ZnO NPs) placed at three different distances $(d=5,10$, and $15 \mathrm{~mm})$. This mimicked different MLS configurations, with the LED properties identical to the ones of the $\mu \mathrm{LP}$. In this case, the irradiance was obtained from Eq. (2). Figure 3(a) shows that the $\mu \mathrm{LP}$ is way more power efficient than the MLS in providing equivalent irradiance conditions.

The devices were then used to activate and measure the photoconductance of the $\mathrm{ZnO}$ layer; that is, lowering the semiconductor resistance under illumination $\left(\Delta R_{\text {light }}=R_{\text {dark }}-R_{\text {light }}\right)$. The material preparation used ${ }^{37}$ displayed (in addition to the
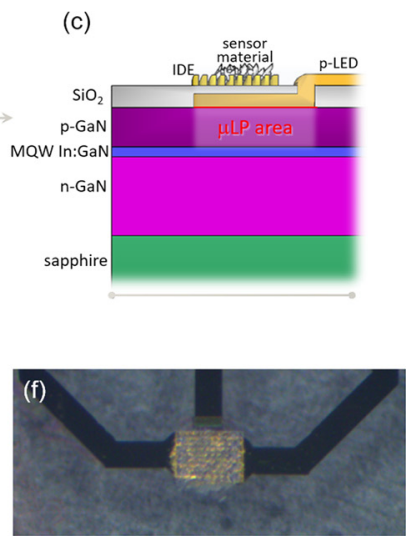

FIG. 2. (a) Schematic view of the $\mu \mathrm{LP}$ devices fabricated in this work. (b) Detailed view of the $\mu \mathrm{LP}$ area containing the active LED region, the IDEs, and the sensor material. (c) Cross section of the device structure across the $\mu \mathrm{LP}$ area. Vertical dimensions are not to scale. Optical microscopy images of the $\mu \mathrm{LP}$ devices: (d) as fabricated, (e) with the LED lit on and (f) with a layer of $\mathrm{ZnO}$ nanoparticles acting as a sensor material. 


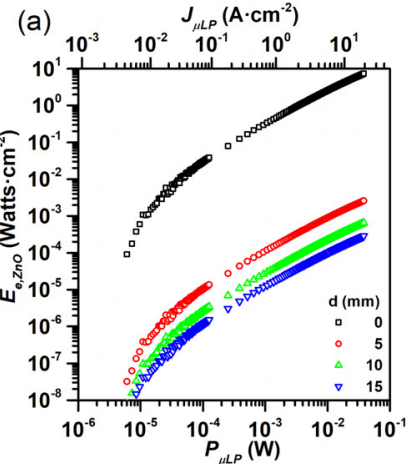

(b)

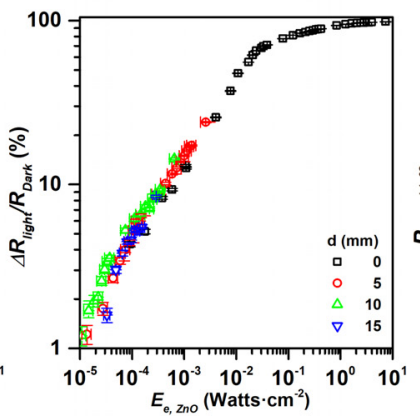

(c)

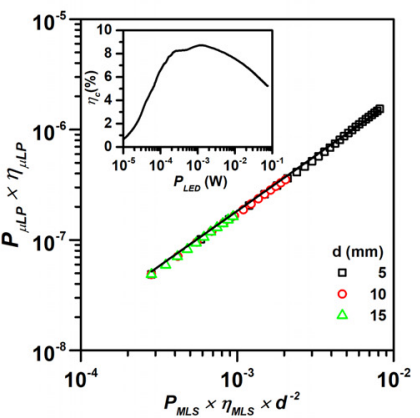

FIG. 3. (a) Irradiance $\left(E_{e}\right)$ as a function of the electrical power $\left(P_{\mu \mathrm{LP}}\right)$ applied to the LED in the $\mu$ LP configuration $(\mathrm{d} \approx 0)$ and in the MLS one at three different distances $(d=5,10$, and $15 \mathrm{~mm})$. (b) Comparison of the photoconductive response of the $\mathrm{ZnO} N$ Ps versus the irradiance impinging on the $\mathrm{ZnO}$ layer when operated in the $\mu \mathrm{LP}$ and in the MLS configuration at 3 different distances. (c) $\left(\eta_{c, \mu \mathrm{LP}} \times P_{\mu \mathrm{LP}}\right) \quad$ plotted versus $\left(P_{\mathrm{MLS}} \times \eta_{c, \mathrm{MLS}} \times d^{-2}\right)$ for the points of (b) corresponding to the same irradiance (interpolated data) usual band-to-band absorption at photon energies above the bandgap of $\mathrm{ZnO}$ ) a broad light adsorption edge in the visible range that overlaps with the emission spectra of the LED in the $\mu \mathrm{LP}$ [see supplementary material S.2.(b)]. Figure 3(b) shows the photoconductance achieved in the $\mu \mathrm{LP}$ and in the MLS configurations. The results show that equivalent irradiance values lead to equivalent photoconductances, demonstrating that irradiance fully rules the optoelectronic response of the devices and, moreover, that both configurations are completely equivalent and consistent with the here-presented geometrical arguments. Thus, for a given irradiance value, we can compare the power needed in the $\mu \mathrm{LP}$ and the MLS approaches by means of the following expression $\left(\mathrm{E}_{e, \mu \mathrm{LP}}=\mathrm{E}_{e, \mathrm{MLS}}=\mathrm{E}=\right.$ const. $)$

$$
\eta_{c, \mu \mathrm{LP}} \times \mathrm{P}_{\mu \mathrm{LP}}=\frac{\left(\mathrm{P}_{\mathrm{MLS}} \times \eta_{c, \mathrm{MLS}}\right)}{\pi \times d^{2}}(w \times l)=\mathrm{E} \times(w \times l),
$$

where the power conversion efficiencies $\eta_{c, \mu L P}$ and $\eta_{c, M L S}$ will have different values because they correspond to different operating points of the LED, as shown in the inset of Fig. 3(c) ( $\eta_{c}$ vS. $\left.P_{L E D}\right)$. To demonstrate the validity of Eq. (4), we present in Fig. 3(c) the plot of $\eta_{c, \mu L P} \times P_{\mu L P}$ versus $P_{M L S} \times \eta_{c, M L S} \times d^{-2}$ for experimental points at the same irradiance taken from Fig. 3(b). Independently on MLS distance used, all points fall within a straight line with a slope differing only by a $6 \%$ from the nominal $(w \times l) / \pi$ prediction, confirming the validity of the here-proposed models for both configurations. Therefore, the $\mu \mathrm{LP}$ device can induce identical effects on the sensor material than the MLS, but with a much lower power consumption. Such a reduction can be obtained systematically by reducing the $\mu \mathrm{LP}$ device area $(w \times l)$ [see also supplementary material S.1.(c)]. Besides, the $\mu$ LP device can cover a broader irradiance range (from $\sim 10^{-4}$ to $10 \mathrm{~W} \cdot \mathrm{cm}^{-2}$ ) than that of the MLS at the shortest distance (from $10^{-5}$ to $2 \times 10^{-3} \mathrm{~W} \cdot \mathrm{cm}^{-2}$ ), thanks to the reduced optical loses (i.e., light spreading).

It could be argued that the photoactivation of the ZnO NPs was due to heat dissipation in the $\mu$ LP. To discard this very plausible effect, we coated several samples with reversible thermochromic inks from Materiales Inteligentes S.L. These experiments demonstrated that the $\mu \mathrm{LP}$ did not exceed $26^{\circ} \mathrm{C}$ (see supplementary material S.3). Therefore, the pronounced effects observed in the photoconductance of the ZnO NP could not be attributed to heating.

Finally, to demonstrate the utility of the $\mu$ LPs to build up useful photoactivated devices, we investigated their responses to low concentrations of $\mathrm{NO}_{2}$ under different illumination conditions (Fig. 4), using a gas mixing setup described elsewhere. ${ }^{38}$ Clearly, it was necessary to turn the LEDs on to activate a reversible response to $\mathrm{NO}_{2}$ in the $\mathrm{ZnO}$ nanoparticles [Fig. 4(a)]. We observed a complex bell-like relationship between the response to $\mathrm{NO}_{2}$ and the irradiance/power values [Fig. 4(b)] with a maximum signal (sensitivity $\mathrm{S}(\%) /\left[\mathrm{NO}_{2}\right]=2250 \% / p p m$ ) at $200 \mu \mathrm{W}$ (equivalent to an irradiance of $60 \mathrm{~mW} \cdot \mathrm{cm}^{-2}$ on the sensor material). Also, irradiance accelerates the response and recovery dynamics of the sensor signal [Fig. 4(a)]. All this is consistent with the models for the photoactivated response of metal oxides to oxidizing gases reported to date qualitatively ${ }^{10,31,39,40}$ and quantitatively. ${ }^{20}$ According to this literature, photogeneration of electron-hole pairs enables additional adsorption and desorption mechanisms for the $\mathrm{NO}_{2}$ target molecules and for the $\mathrm{O}_{2}$ present in the background air. As a result, light moderates the competence between both species, enabling new adsorption/desorption equilibriums at room temperature that are not possible in dark conditions. It is remarkable that these functionalities could be achieved with electrical power
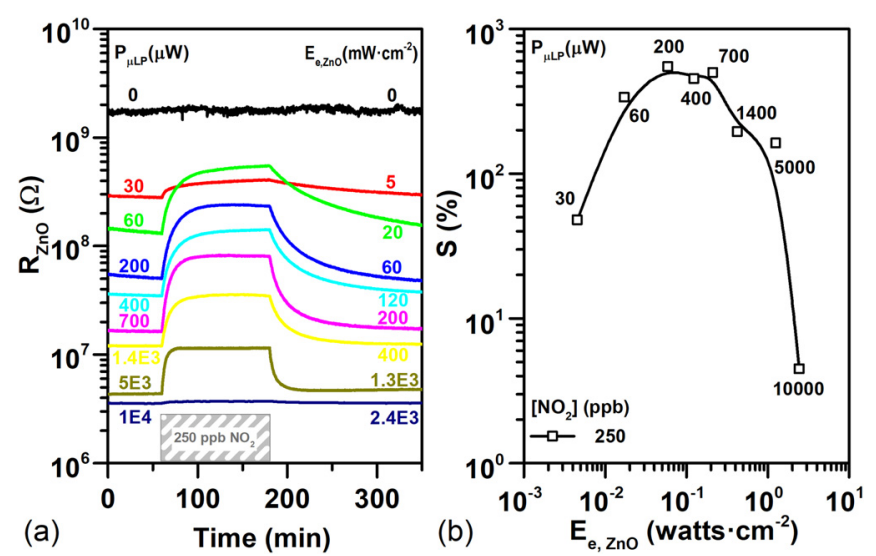

FIG. 4. Photoactivated response to $\mathrm{NO}_{2}$ of a $\mu \mathrm{LP}$-based $\mathrm{ZnO}$ sensor under different LED light intensities ( $P_{\mu \mathrm{LP}}$ and $E_{e, \mathrm{ZnO}}$ indicated). (a) Record of the $\mathrm{ZnO}$ nanoparticle resistance over time upon exposure to one gas pulse of $250 \mathrm{ppb}$ of $\mathrm{NO}_{2}$ diluted in synthetic dry air. (b) Summary of the responses (defined as the relative change of the sensor resistance in the presence of $\mathrm{NO}_{2}$ with respect to that in synthetic air $(\mathrm{SA}), S(\%)=\left(\left(R_{\mathrm{NO}_{2}}-R_{\mathrm{SA}}\right) / R_{\mathrm{SA}}\right)$. 
consumptions as low as $30 \mu \mathrm{W}$ (irradiance of $5 \mathrm{~mW} \cdot \mathrm{cm}^{-2}$ ), demonstrating the utility of the $\mu \mathrm{LP}$ to produce fully functional gas sensors with power consumptions much lower than those reported for conventional heated devices and in previous works operating with light-activated devices. ${ }^{10}$

In summary, the micro light plate $(\mu \mathrm{LP})$ configuration offers a direct path towards lowering the power consumption of light activated devices, because of the following concurrent factors: (a) the efficiency of the LED technology to convert electrical energy into light compared to other illumination systems, (b) the close distance between the light source and the sensor material (a few hundred nanometers), and (c) the independence between the LED area and the resulting irradiance impinging on the sensor. We presented the general framework that rules the design and systematic optimization of the $\mu \mathrm{LP}$ configuration, and demonstrated its validity and full functional equivalence to conventional approaches (MLS), with power requirements (e.g., $30 \mu \mathrm{W}$ to detect $250 \mathrm{ppb}$ of $\mathrm{NO}_{2}$ with $\mathrm{ZnO} \mathrm{NPs}$ ) much lower than those found in the state of the art. Moreover, the $\mu \mathrm{LPs}$ provide unprecedented levels of control and reproducibility of the illumination conditions in a device that can be reproduced in large volumes with conventional microelectronic processing. With the here-presented strategy, these advantages can be incorporated to all sorts of integrated systems that require local illumination.

See supplementary material for the derivation of the irradiance model used in this work (S.1), further experimental details (S.2), and experimental determination of the temperature increase in the devices under operation (S.3).

This work has been carried out within the EU Project of "BetterSense - Nanodevice Engineering for Better Chemical Gas Sensing Technology" funded by the European Research Council under Grant Agreement No. 336917 and LENAOptoSense funded by the Lower Saxony Ministry for Science and Culture (N-MWK). O. Casals thanks the support of the TecnioSpring fellowship programme of ACCIÓ, Government of Catalonia, co-funded by the EU Marie Curie Action COFUND. J. D. Prades acknowledges the support of the Serra Húnter Program and the DFG Project GRK NanoMet. This research has made use of the infrastructure of the Spanish ICTS Network MICRONANOFABS partially supported by MINECO.

\section{REFERENCES}

${ }^{1}$ D. Yin, J. P. Barber, A. R. Hawkins, and H. Schmidt, Appl. Phys. Lett. 87, 211111 (2005).

${ }^{2}$ G. Ryu, J. Huang, O. Hofmann, C. A. Walshe, J. Y. Y. Sze, G. D. McClean, A. Mosley, S. J. Rattle, J. C. Demello, A. J. Demello, and D. D. C. Bradley, Lab Chip 11, 1664 (2011).

${ }^{3}$ F. Cellini, S. D. Peterson, and M. Porfiri, Appl. Phys. Lett. 110, 221904 (2017).

4J. Parmar, S. Jang, L. Soler, D. P. Kim, and S. Sánchez, Lab Chip 15, 2352 (2015).

${ }^{5}$ J. Huang and Q. Wan, Sensors 9, 9903 (2009).

${ }^{6}$ N. L. W. Septiani and B. Yuliarto, J. Electrochem. Soc. 163, B97 (2016).
${ }^{7}$ S. Semancik, R. E. Cavicchi, M. C. Wheeler, J. E. Tiffany, G. E. Poirier, R. M. Walton, J. S. Suehle, B. Panchapakesan, and D. L. DeVoe, Sens. Actuators, B 77, 579 (2001).

${ }^{8}$ P. Bhattacharyya, IEEE Trans. Device Mater. Reliab. 14, 589 (2014).

${ }^{9}$ C. Fàbrega, O. Casals, F. Hernández-Ramírez, and J. D. Prades, Sens Actuators, B 256, 797-811 (2018).

${ }^{10}$ E. Espid and F. Taghipour, Crit. Rev. Solid State Mater. Sci. 42, 416 (2017).

${ }^{11}$ J. Puigcorbé, D. Vogel, B. Michel, A. Vilà, I. Gràcia, C. Cané, and J. R. Morante, J. Micromech. Microeng. 13, 548 (2003).

${ }^{12}$ T. Iwaki, J. A. Covington, J. W. Gardner, F. Udrea, C. S. Blackman, and I. P. Parkin, IEEE Sensors 2006, Daegu, Korea, 22-25 October (2006).

${ }^{13}$ I. Elmi, S. Zampolli, E. Cozzani, F. Mancarella, and G. C. Cardinali, Sens. Actuators, B 135, 342 (2008).

${ }^{14}$ S. Vallejos, I. Grácia, O. Chmela, E. Figueras, J. Hubálek, and C. Cané, Sens. Actuators, B 235, 525 (2016).

${ }^{15}$ B. Martinez, M. Monton, I. Vilajosana, and J. D. Prades, IEEE Sens. J. 15, 5777 (2015).

${ }^{16}$ E. Comini, A. Cristalli, G. Faglia, and G. Sberveglieri, Sens. Actuators, B 65, 260 (2000).

${ }^{17}$ E. Comini, G. Faglia, and G. Sberveglieri, Sens. Actuators, B 78, 73 (2001).

${ }^{18}$ M. Kumar, A. V. Agrawal, R. Kumar, S. Venkatesan, A. Zakhidov, G. Yang, and J. Bao, ACS Sens. 3, 998 (2018).

${ }^{19}$ C. Y. Wang, V. Cimalla, T. Kups, C. C. Röhlig, T. Stauden, O. Ambacher, M. Kunzer, T. Passow, W. Schirmacher, W. Pletschen, K. Köhler, and J. Wagner, Appl. Phys. Lett. 91, 103509 (2007).

${ }^{20}$ J. D. Prades, R. Jimenez-Diaz, M. Manzanares, F. Hernandez-Ramirez, A. Cirera, A. Romano-Rodriguez, S. Mathur, and J. R. Morante, Phys. Chem. Chem. Phys. 11, 10881 (2009).

${ }^{21}$ J. D. Prades, R. Jimenez-Diaz, F. Hernandez-Ramirez, S. Barth, A. Cirera, A. Romano-Rodriguez, S. Mathur, and J. R. Morante, Sens. Actuators, B 140, 337 (2009).

22J. Sun, J. Xu, Y. Yu, P. Sun, F. Liu, and G. Lu, Sens. Actuators, B 169, 291 (2012).

${ }^{23}$ J. H. Yu, H. J. Yang, H. S. Mo, T. S. Kim, T. S. Jeong, C. J. Youn, and K. J. Hong, J. Electron. Mater, 42, 720 (2013).

${ }^{24}$ Y. H. Kim, S. J. Kim, Y. J. Kim, Y. S. Shim, S. Y. Kim, B. H. Hong, and H. W. Jang, ACS Nano 9, 10453 (2015).

${ }^{25}$ J. Guilera, C. Fàbrega, O. Casals, F. Hernández-Ramírez, S. Wang, S. Mathur, F. Udrea, A. De Luca, S. Z. Ali, A. Romano-Rodríguez, J. D. Prades, and J. R. Morante, Sens. Actuators, B 221, 104 (2015).

${ }^{26}$ R. Jaisutti, M. Lee, J. Kim, S. Choi, T. J. Ha, J. Kim, H. Kim, S. K. Park, and Y. H. Kim, ACS Appl. Mater. Interfaces 9, 8796 (2017).

${ }^{27}$ B. Gong, T. Shi, W. Zhu, G. Liao, X. Li, J. Huang, T. Zhou, and Z. Tang, Sens. Actuators, B 245, 821 (2017).

${ }^{28}$ C. L. Hsu, L. F. Chang, and T. J. Hsueh, Sens. Actuators, B 249, 265 (2017).

${ }^{29}$ T. Xie, N. Sullivan, K. Steffens, B. Wen, G. Liu, R. Debnath, A. Davydov, R. Gomez, and A. Motayed, J. Alloys Compd. 653, 255 (2015).

${ }^{30}$ T. Xie, A. Rani, B. Wen, A. Castillo, B. Thomson, R. Debnath, T. E. Murphy, R. D. Gomez, and A. Motayed, Thin Solid Films 620, 76 (2016).

${ }^{31}$ C. Zhang, A. Boudiba, P. De Marco, R. Snyders, M. G. Olivier, and M. Debliquy, Sens. Actuators, B 181, 395 (2013).

${ }^{32}$ E. F. Zalewski, in Handbook of Optics, Devices, Measurement and Properties, 2nd ed., edited by M. Bass (McGraw-Hill, Inc., 1995), Vol. 2.

${ }^{33}$ W. J. Smith, Modern Optical Engineering, 3rd ed. (McGraw-Hill, 2000).

${ }^{34}$ A. D. Ryer, Light Measurement Handbook (International Light, 1998).

${ }^{35}$ Labsphere Tech Guide: Radiometry of Light Emitting Diodes, Labsphere Inc., available at https://www.labsphere.com/site/assets/files/2570/ the-radiometry-of-light-emitting-diodes-leds.pdf.

${ }^{36}$ T. Rossi, T. J. Penfold, M. H. Rittmann-Frank, M. Reinhard, J. Rittmann, C. N. Borca, D. Grolimund, C. J. Milne, and M. Chergui, J. Phys. Chem. C 118, 19422 (2014)

${ }^{37}$ Q. Zhang, K. Park, and G. Cao, Mater. Matters 5, 32 (2010).

${ }^{38} \mathrm{O}$. Casals, T. Becker, P. Godignon, and A. Romano-Rodriguez, Sens Actuators, B 175, 60 (2012).

${ }^{39}$ E. Espid and F. Taghipour, Sens. Actuators, B 241, 828 (2017).

${ }^{40}$ E. Espid and F. Taghipour, ECS J. Solid State Sci. Technol. 7, Q3089 (2018). 